\title{
SESAMOL ANTAGONIZES ROTENONE-INDUCED CELL DEATH IN SH-SY5Y NEURONAL CELLS
}

\author{
ROHINI D. ${ }^{1}$, VIJAYALAKSHMI K.2* \\ 1,2Department of Biochemistry, Bharathi Women's College, Chennai, Tamil Nadu, India \\ Email: viji42research@yahoo.co.in
}

Received: 06 Aug 2016 Revised and Accepted: 05 Oct 2016

\begin{abstract}
Objective: To investigate the neuroprotective effect of sesamol against rotenone-induced cell death in SH-SY5Y cells associated with Parkinsonism.

Methods: SH-SY5Y cells were maintained in Dulbecco's modified Eagle's medium. After differentiation, the cells were incubated with rotenone (20 $\mu \mathrm{M})$ and sesamol at different concentrations $(10-100 \mu \mathrm{M})$. Cell viability was determined by 3-(4,5-dimethylthiazol-2-yl)-2,5-diphenyl-tetrazolium bromide assay. The reactive oxygen species, mitochondrial membrane potential and nuclear morphology were determined by dichlorofluorescein diacetate, rhodamine 123 and 4', 6-diamidino-2-phenylindole, respectively. Thiobarbituric acid reactive substances, activities of catalase, superoxide dismutase, and glutathione peroxidase and glutathione level were determined by standard assays.
\end{abstract}

Results: Sesamol significantly increased the cell viability and decreased the rotenone-induced cell death in SH-SY5Y cells. Sesamol antagonized rotenone-induced reactive oxygen species generation, loss of mitochondrial membrane potential and nuclear damage. Sesamol also decreased thiobarbituric acid reactive substances level, increased the activities of catalase, superoxide dismutase, glutathione peroxidase and increased the level of glutathione in rotenone-induced cells.

Conclusion: The results obtained strongly indicate the promising neuroprotective role of sesamol against rotenone-induced death in SH-SY5Y cells.

Keywords: Parkinson's disease, SH-SY5Y cells, Rotenone, Sesamol, Neuroprotection

(C) 2016 The Authors. Published by Innovare Academic Sciences Pvt Ltd. This is an open access article under the CC BY license (http://creativecommons.org/licenses/by/4. 0/) DOI: http://dx.doi.org/10.22159/ijpps.2016v8i12.14529

\section{INTRODUCTION}

Parkinson's disease (PD) is an overwhelming neurodegenerative movement disorder in industrialized countries. Clinical features of PD include motor impairments involving resting tremor, bradykinesia postural instability and rigidity [1]. Several toxicant-induced model systems have been developed to study Parkinson's disease including rotenone (ROT), MPTP (1-methyl-4-phenyl-1,2,3,6-tetrahydropyridine), 6-hydroxydopamine (6-OHDA) and paraquat [2]. In the human population, the increased risk of PD is associated with exposure to organic pesticide such as ROT [3]. These findings have renewed interest in the link between exposure to pesticides and the development of Parkinson's disease [4]. ROT is a hydrophobic natural pesticide that attributes the irreversible binding and inactivation of NADH-ubiquinone reductase (complex I) in the mitochondrial electron transport chain [5]. It has been demonstrated that ROT administration in rats develops biochemical, anatomical and behavioral symptoms of Parkinson's disease [6, 7]. ROT model for PD is a highly reproducible model and provides an excellent tool to test novel neuroprotective strategies [8]. PD is currently treated with L-DOPA (L-dihydroxy phenylalanine). Long-term administration of L-DOPA has many side effects including abnormal involuntary movements, i.e., L-DOPAinduced dyskinesia [9]. Hence, we planned to study the natural ingredients present in plants to prevent PD. Oxidative stress is a hallmark feature in the progression of PD and therefore treatment with drugs that have powerful antioxidant properties can nullify the cellular damage. Fakhrudin, et al. [10] reported that natural free radical scavenger could provide antioxidant mechanisms to nullify the negative effects in cells. Sesamol (SES) (5-hydroxy-1,3-benzodioxole) fig.1, a phytonutrient of the class lignans is present in sesame [11]. Khadira Screen and Vijayalakshmi have reported SES as an efficient antioxidant [12] which protects the cells from free radical injury. SES is a traditionally used health supplement which exerts photoprotective [13], chemopreventive [14], hepatoprotective [15], antiinflammatory [16], anti-aging [17] and anti-depressant [18] activities. SH-SY5Y cells exhibits neuronal marker enzymes like tyrosine hydroxylase, dopamine-beta-hydroxylase, dopamine transporters and neuroinflammation proteins [19]. Hence, SH-SY5Y has been reported as an ideal cellular model for Parkinson's disease [20]. The rationale of the study is to investigate the neuroprotective role of SES in ROTinduced SH-SY5Y cells.

\section{MATERIALS AND METHODS}

Rotenone, sesamol, retinoic acid, 3-(4,5-dimethylthiazol-2-yl)-2,5diphenyl-tetrazolium bromide (MTT), dichlorofluorescein diacetate (DCFH-DA), rhodamine 123, 4',6-diamidino-2-phenylindole (DAPI), dimethyl sulphoxide (DMSO), Dulbecco's modified Eagle's medium (DMEM), fetal bovine serum (FBS) and other tissue culture reagents were purchased from Sigma-Aldrich (St. Louis, Missouri, USA).

\section{Cell culture}

The SH-SY5Y cells were obtained from the National Centre for Cell Science (NCCS), Pune, India. Cells were maintained in DMEM with $15 \%$ FBS, L-glutamine, $100 \mathrm{U} / \mathrm{ml}$ penicillin/streptomycin in $95 \%$ humidified air and $5 \% \mathrm{CO}_{2}$ incubator at $37{ }^{\circ} \mathrm{C}$. For every two days, the media was changed and then $10 \mu \mathrm{M}$ of retinoic acid was used for $7 \mathrm{~d}$ for differentiation before analysis. ROT and SES were freshly prepared in DMSO and saline respectively prior to each experiment. The final concentration of DMSO in the medium was always less than $0.1 \%$, and it has shown no effects on cell viability. The effective dose of SES was used to identify the potential neuroprotective effect against ROT-induced cells.

\section{Cell viability assay}

The cell viability was done by MTT quantitative assay according to Van Meerlo et al. [21]. This sensitive assay is based on the conversion of MTT into formazon crystals by living cells, which determine the mitochondrial activity. From the amount of formazon produced, the number of viable cells was determined.

The differentiated SH-SY5Y cells were seeded in 96 well plates with density $1 \times 10^{5}$ cells/well and incubated for $24 \mathrm{~h}$ at $37^{\circ} \mathrm{C}$. Then cells were incubated with ROT $(20 \mu \mathrm{M})$ followed by Song et al. [22] and the simultaneous treatment with SES at different concentrations $(10-100 \mu \mathrm{M})$ was carried out and incubated. After $24 \mathrm{~h}, 10 \mu \mathrm{l}$ of MTT was added to each well and incubated for $4 \mathrm{~h}$ at $37^{\circ} \mathrm{C}$. The absorbance was read at $570 \mathrm{~nm}$. The percentage of cell viability was calculated by the formula: 
Cell viability (\%) $=\left[\frac{\text { Optical Density of Test }(570 \mathrm{~nm})}{\text { Optical Density of Control }(570 \mathrm{~nm})}\right] \times 100$ Determination of intracellular reactive oxygen species (ROS)

The intracellular ROS generation induced by ROT in SH-SY5Y cells was determined using DCFH-DA according to the method described by Wang and Joseph [23]. DCFH-DA, a redox-sensitive dye gets enzymatically hydrolyzed by intracellular esterases to nonfluorescent DCFH. In the presence of ROS, DCFH rapidly gets oxidized to highly fluorescent 2',7'-dichlorofluorescein (DCF).

The SH-SY5Y cells were plated at a density of $1 \times 10^{5}$ cells/well. The cells were exposed to ROT $(20 \mu \mathrm{M})$ with and without SES $(50 \mu \mathrm{M})$ at $37^{\circ} \mathrm{C}$. After $24 \mathrm{~h}$, the media was removed and phosphate-buffered saline (PBS), pH 7.2 was used to wash the cells. The cells were treated with $10 \mu \mathrm{M}$ of DCFH-DA and incubated for $1 \mathrm{hr}$ at $37^{\circ} \mathrm{C}$. The fluorescence was observed under a fluorescent microscope and measured at excitation and emission wavelength of 485 and $530 \mathrm{~nm}$.

\section{Changes in mitochondrial membrane potential}

Mitochondrial dysfunction plays a key role in the initiation of cell death and the mitochondrial membrane potential is affected by the apoptotic factors. The recorded change in the mitochondrial membrane potential in SH-SY5Y cells was visualized using rhodamine 123 according to the method described by Baracca et al. [24]. SH-SY5Y cells were plated at a density of $1 \times 10^{5} \mathrm{cells} /$ well and exposed to ROT $(20 \mu \mathrm{M})$ with and without SES $(50 \mu \mathrm{M})$. The cells were washed with PBS after $24 \mathrm{~h}$. Then the cells were incubated with $5 \mu \mathrm{g} / \mathrm{ml}$ of rhodamine 123 at $37^{\circ} \mathrm{C}$ for $30 \mathrm{~min}$. The fluorescence was observed under a fluorescent microscope and measured at excitation and emission wavelength of 488 and $525 \mathrm{~nm}$.

\section{Nuclear morphology assessment}

The alterations in the nuclear morphology of SH-SY5Y cells were observed by DAPI staining method of Morikawa and Yanagida [25]. The SH-SY5Y cells were plated at a density of $1 \times 10^{5}$ cells/well. The cells were exposed to ROT $(20 \mu \mathrm{M})$ with and without SES $(50 \mu \mathrm{M})$ and incubated at $37^{\circ} \mathrm{C}$. After $24 \mathrm{~h}$, the media was removed, and PBS was used to wash the cells. The cells were treated with $1 \mu \mathrm{g} / \mathrm{ml}$ DAPI fluorescence dye and incubated for $1 \mathrm{hr}$ at $37^{\circ} \mathrm{C}$. The fluorescence was observed under a fluorescent microscope and measured at excitation and emission wavelength of 350 and $470 \mathrm{~nm}$.

\section{Thiobarbituric acid reactive substances (TBARS) assay}

TBARS is a method for the quantification of lipid peroxidation by Ottolenghi [26]. 20\% trichloroacetic acid and $0.67 \%$ 2-thiobarbituric acid were mixed with homogenate. The mixture was placed in a boiling water bath for $20 \mathrm{~min}$. After cooling, the mixture was centrifuged at $3000 \mathrm{rpm}$ for $20 \mathrm{~min}$. The absorbance of the supernatant was measured at $530 \mathrm{~nm}$. The lipid peroxide content was expressed as $\mathrm{nmol} / \mathrm{mg}$ of protein.

\section{Antioxidant activities-enzymatic antioxidants \\ Assay of catalase (CAT) (EC 1.11.1.6)}

CAT activity was assayed in cell homogenate mixture containing 100 mmol disodium hydrogen phosphate $\left(\mathrm{Na}_{2} \mathrm{HPO}_{4}\right)$ buffer and $30 \mathrm{mmol}$ hydrogen peroxide $\left(\mathrm{H}_{2} \mathrm{O}_{2}\right)$ by the method of Aebi [27]. The decrease in absorbance due to $\mathrm{H}_{2} \mathrm{O}_{2}$ depletion was monitored at $240 \mathrm{~nm}$. The CAT activity was expressed as $\mu$ moles of $\mathrm{H}_{2} \mathrm{O}_{2}$ utilized $/ \mathrm{min} / \mathrm{mg}$ of protein.

\section{Assay of superoxide dismutase (SOD) (EC 1.15.1.1)}

SOD activity was assayed by the method based on the inhibition of the formation of nicotinamide adenine dinucleotide, phenazine methosulphate and nitro-blue tetrazolium (NADH-PMS-NBT) complex followed by Kakkar et al. [28]. The colour formed was measured at $560 \mathrm{~nm}$. The SOD activity was expressed as the amount of enzyme required to inhibit $50 \%$ NBT reduction in $1 \mathrm{~min}$.

\section{Assay of glutathione peroxidase (GPx) (E. C. No 1.11.1.9)}

GPx activity was assayed in cell homogenate mixture containing 0.8 mmol EDTA (ethylenediaminetetraacetic acid), $10 \mathrm{mmol}$ sodium azide, $2.5 \mathrm{mmol}$ hydrogen peroxide and $0.32 \mathrm{mmol}$ phosphate buffer according to the protocol of Rotruck et al. [29]. The absorbance was monitored at $420 \mathrm{~nm}$. The GPx activity was expressed as $\mu$ moles of glutathione utilized $/ \mathrm{min} / \mathrm{mg}$ of protein.

\section{Non-enzymatic antioxidant}

\section{Estimation of glutathione (GSH)}

The GSH content was measured in cell homogenate mixture containing $10 \%$ trichloroacetic acid, $0.2 \mathrm{M}$ phosphate buffer and 0.6 mmol 5, 5'-dithiobis-2-nitrobenzoic acid (DTNB) according to Moron et al. [30]. The absorbance was read at $412 \mathrm{~nm}$. The amount of GSH was expressed as nmol/mg of protein.

\section{Statistical analysis}

The statistical analysis was performed using SPSS version 20 from IBM. The results were expressed as mean $\pm S D$. One-way analysis of variance was applied to the data and the significance of the results was derived by running post hoc test. The $\mathrm{p}<0.05$ were considered statistically significant.

\section{RESULTS AND DISCUSSION}

In this study, we evaluated the neuroprotective effect of SES on ROTinduced SH-SY5Y cells. In the neurotoxic model 6-OHDA of PD Khadira Sereen et al. reported SES as an anti-Parkinson compound [31]. Van Gilder and Huber reported that SES can treat neuropathic pain and restore the blood-brain barrier function [32].

Cell viability was examined by MTT assay. Inhibition of cellular respiration in SH-SY5Y cells by ROT results in the compensatory induction of glycolysis, loss of bioenergetics reserve capacity and activation of apoptotic cascade as reported by Giordano et al. [33] Anusha et al. demonstrated that ROT-induced cell death [34] by apoptotic mechanism and this coincides with our result that the cell viability was decreased with ROT $(20 \mu \mathrm{M})$ treatment. The maximum cell viability was found at $50 \mu \mathrm{M}$ SES when co-treated with ROT and on a further increase of SES concentration at $100 \mu \mathrm{M}$, the viability was at steady state. Fig. 2 and 3 show the effect of SES on the viability of SH-SY5Y cells. SES shows no toxicity at these concentrations. SES $(100 \mu \mathrm{M})$ alone treated cells show similar results as vehicle control. Our observation is consistent with Liu et al. that curcumin, a potent antioxidant has protected SH-SY5Y cells from ROT damage [35].

The excessive accumulation of ROS and inefficiency of the antioxidant enzymes results in DNA damage, lipid peroxidation, cellular dysfunction and apoptosis [36]. SH-SY5Y cells induced with ROT lead to ROS production as shown in the experiments with the fluorescent dye DCFH-DA (fig. 4). SH-SY5Y cells exposed to ROT show a significant increase in DCF fluorescence whereas there is decreased fluorescence in cells co-treated with ROT $(20 \mu \mathrm{M})$ and SES $(50 \mu \mathrm{M})$. Co-treatment with SES shows a significant loss in green fluorescence which suggests that ROS generation was inhibited. SES $(100 \mu \mathrm{M})$ alone treated cells show similar results as vehicle control. The results indicate that SES against ROT could act as an antioxidant and free radical scavenger. Liu et al. reported that ROT treatment initiated ROS production, caspase 3 activation and lactic acid accumulation in PC12 cells [37]. Most of the existing reports suggest that the oxidative stress and mitochondrial dysfunction plays a critical role in the pathogenesis of neurodegeneration in PD [38].

Rhodamine 123 staining indicates the mitochondrial membrane potential in SH-SY5Y cells (fig. 5). Chinnaiyan et al. reported that the loss of mitochondrial membrane potential increases the mitochondrial permeability and results in the release of cytochrome c, which triggers the activation of caspase $9 / 3$ and ultimate cell death [39]. Dhanalakshmi et al. reported that ROT had decreased the mitochondrial membrane potential in SH-SY5Y cells [40] which coincide with our result. Decreased fluorescent intensity represented a drop in the mitochondrial membrane potential when the cells were induced with ROT $(20 \mu \mathrm{M})$. Due to the mitochondrial membrane potential loss in ROT exposed cells, the dye was released into the cytosol. The co-treatment with SES $(50 \mu \mathrm{M})$ significantly inhibited the decrease in mitochondrial membrane potential triggered by ROT. SES $(100 \mu \mathrm{M})$ alone treated cells show similar results as vehicle control.

DAPI staining indicates the nuclear morphology of SH-SY5Y cells (fig. 6). Kim et al. reported that on ROT induction, the nuclear damage was found to be high [41] which correlated with our study 
when ROT $(20 \mu \mathrm{M})$ was induced in SH-SY5Y cells. Decreased nuclear damage was found during the co-treatment with SES $(50 \mu \mathrm{M})$. SES $(100 \mu \mathrm{M})$ alone treated cells show no alterations in nuclear morphology and are similar to vehicle control. Lin et al. reported that resveratrol, a polyphenolic stilbene prevented nuclear damage induced by ROT [42] and this correlates with our study.

Joshi et al. reported that SES can prevent lipid peroxidation, hydroxyl radical-induced deoxyribose degradation and DNA damage [43]. When cells were induced with ROT $(20 \mu \mathrm{M})$, there was an increased level of TBARS indicating the increased production of free radical along with glutathione exhaustion (fig. 7). Co-treatment with SES $(50 \mu \mathrm{M})$ decreased the TBARS level. SES $(100 \mu \mathrm{M})$ alone treated cells show similar results as vehicle control. SES, a powerful antioxidant inhibits lipid peroxidation [44] as reported by Prasad et al.

Fig. 8-11 shows the activities of CAT, SOD, GPx and the level of GSH in ROT-induced SH-SY5Y cells with and without SES. Chandra et al. reported that decrease in antioxidant enzyme activities is closely related to the induction of lipid peroxidation [45]. The ROT $(20 \mu \mathrm{M})$ induced SH-SY5Y cells showed decreased activities of CAT, SOD, GPX and decreased the level of GSH due to the high ROS production whereas co-treatment with SES $(50 \mu \mathrm{M})$ significantly increased their levels. The other possible mechanism such as the ability of SES to enhance the glutathione content could be involved in its protective effect on ROT-induced oxidative stress. SES $(100 \mu \mathrm{M})$ alone treated cells show similar results as vehicle control. CAT plays an important role in protecting SH-SY5Y cells from ROS-related diseases including PD [46]. Zhou et al. suggest that administering antioxidants can block the ROT-induced ROS in primary neurons, PC12 cells and could provide a promising strategy for prevention and treatment of PD [47]. SOD, a potent enzyme involved in the detoxification of ROS and protects against oxidative stress and prevent neuronal cells from apoptosis [48]. GSH is a major endogenous antioxidant that counteracts free radical mediated injuries [49]. GSH retains the mitochondrial redox environment to repair oxidative modifications leading to mitochondrial dysfunction and cell death [50]. Isenberg and Klauing [51] observed that ROT exposure could cause the loss of intracellular glutathione by membrane leakage. Our results demonstrated that both the free radical generation and mitochondrial dysfunction were responsible for ROT-induced cell death in SH-SY5Y cells. Co-treatment with SES has enhanced the antioxidant status and suppressed the observed antagonistic events due to ROT.<smiles>Oc1ccc2c(c1)OCO2</smiles>

Fig. 1: Shows the structure of sesamol $\left(\mathrm{C}_{7} \mathrm{H}_{6} \mathrm{O}_{3}\right)$

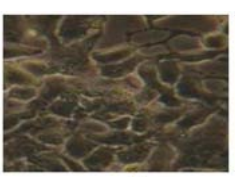

A

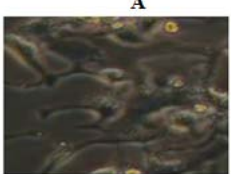

D
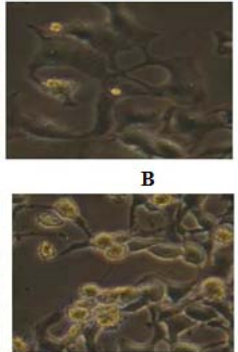

$\mathbf{E}$

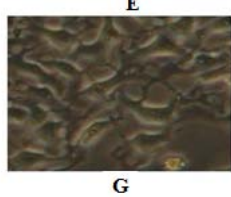

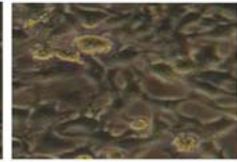

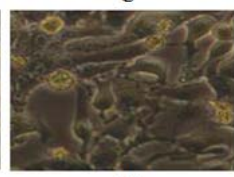

Fig. 2: Shows the result of cell viability assay: A-Vehicle control, B-Rotenone (ROT) $20 \mu \mathrm{M}$ shows increased cell death as compared to vehicle control cells, C-Sesamol (SES) $100 \mu \mathrm{M}$, DRotenone (ROT) $20 \mu \mathrm{M}+$ Sesamol (SES) $10 \mu \mathrm{M}$, E-Rotenone (ROT) $20 \mu \mathrm{M}+$ Sesamol (SES) $25 \mu \mathrm{M}$, F-Rotenone (ROT) 20 $\mu \mathrm{M}+$ Sesamol (SES) $50 \mu \mathrm{M}$, G-Rotenone (ROT) $20 \mu \mathrm{M}+$ Sesamol (SES) $100 \mu \mathrm{M}$. D,E,F,G-shows decreased cell death as compared to Rotenone (ROT) $20 \mu \mathrm{M}$ induced cells. Magnification-40X

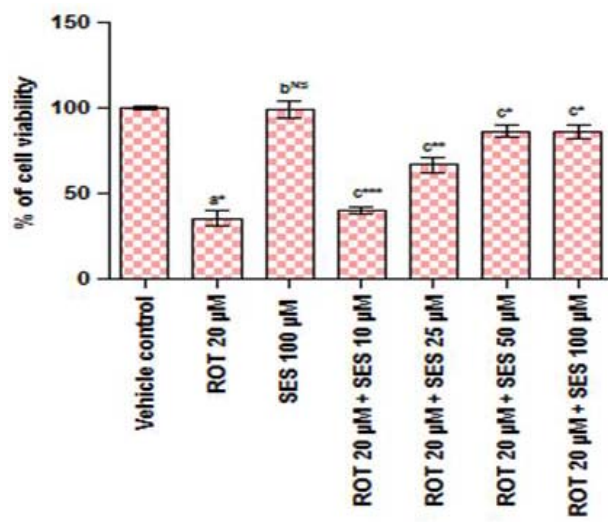

Fig. 3: Shows the percentage of cell viability. statistical significance: ${ }^{*} \mathbf{P}<0.001,{ }^{* *} \mathbf{P}<0.01$ and ${ }^{* * *} \mathbf{P}<0.05$; NS-nonsignificant; $n=3$, a comparison between Vehicle control and Rotenone (ROT), b-comparison between Vehicle control and Sesamol (SES), c-comparison between rotenone (ROT) and rotenone (ROT)+Sesamol (SES)

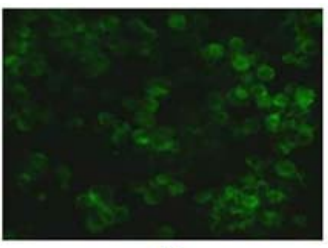

$\mathbf{A}$

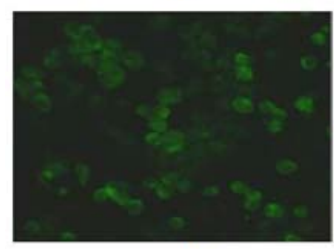

C

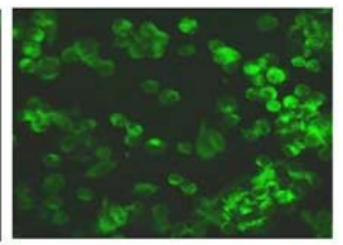

B

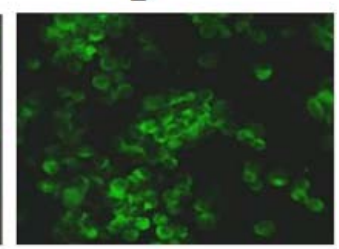

D
Fig. 4: Shows the determination of intracellular reactive oxygen species (ROS): A-Vehicle control, B-Rotenone (ROT) $20 \mu \mathrm{M}$ shows increased level of reactive oxygen species (ROS) as compared to vehicle control cells, C-Sesamol (SES) $100 \mu \mathrm{M}, \mathrm{D}$ Rotenone (ROT) $20 \mu \mathrm{M}+$ Sesamol (SES) $50 \mu \mathrm{M}$ shows decreased level of reactive oxygen species (ROS) as compared to Rotenone (ROT) $20 \mu \mathrm{M}$ induced cells. Magnification-40X
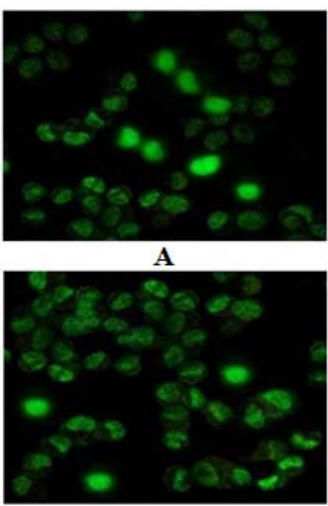

C
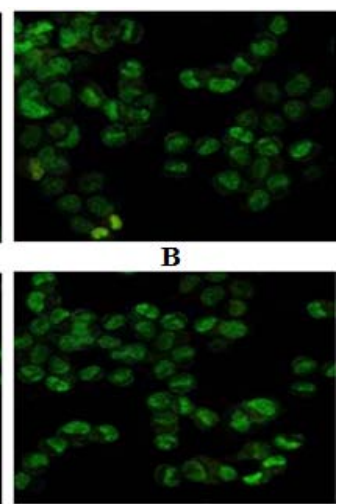

D
Fig. 5: Shows the changes in mitochondrial membrane potential: A-Vehicle control, B-Rotenone (ROT) $20 \mu \mathrm{M}$ shows decreased mitochondrial membrane potential as compared to vehicle control cells, C-Sesamol (SES) $100 \mu \mathrm{M}$, D-Rotenone

(ROT) $20 \mu \mathrm{M}+$ Sesamol (SES) $50 \mu \mathrm{M}$ shows increased mitochondrial membrane potential as compared to Rotenone (ROT) $20 \mu \mathrm{M}$ induced cells. Magnification-40X 


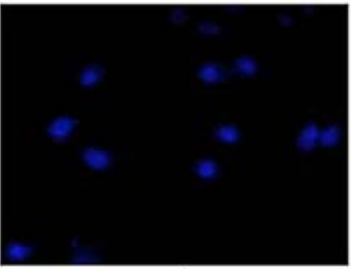

$\mathbf{A}$

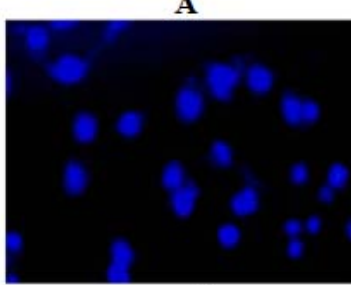

C

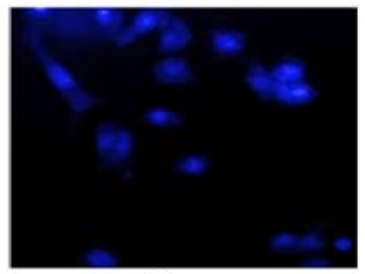

B

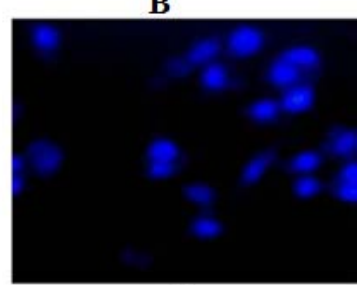

D

Fig. 6: Shows the nuclear morphology assessment: A-Vehicle control, B-Rotenone (ROT) $20 \mu \mathrm{M}$ shows increased nuclear damage as compared to vehicle control cells, C-Sesamol (SES) $100 \mu \mathrm{M}$, D-rotenone (ROT) $20 \mu \mathrm{M}+$ Sesamol (SES) $50 \mu \mathrm{M}$ shows decreased nuclear damage as compared to rotenone (ROT) 20 $\mu \mathrm{M}$ induced cells. Magnification-40X
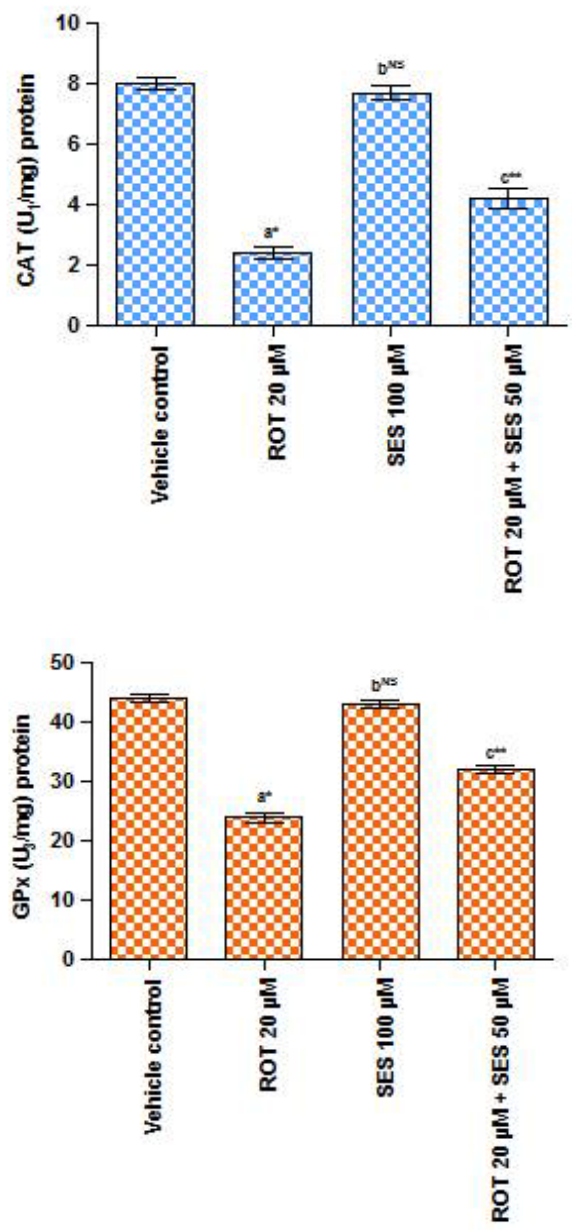

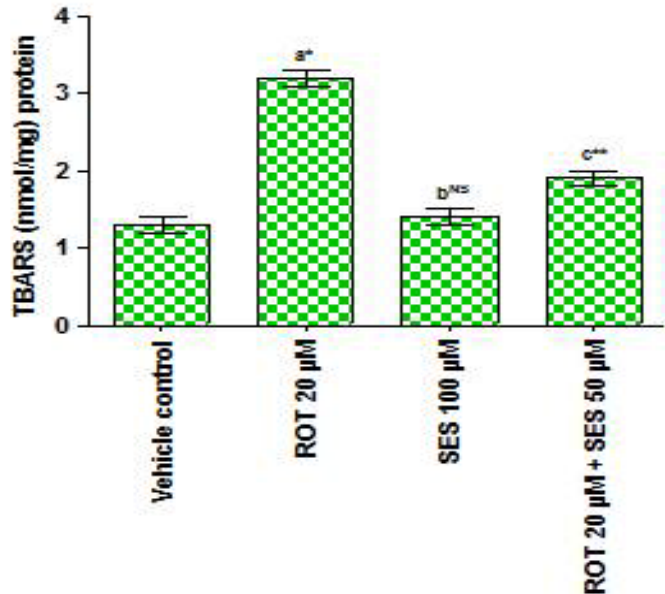

Fig.7: Shows the estimation of thiobarbituric acid reactive substances (TBARS). Statistical significance: ${ }^{*} \mathrm{P}<0.001$ and ${ }^{* *} \mathrm{P}<0.01$; NS-non-significant; $\mathrm{n}=3$, a comparison between Vehicle control and Rotenone (ROT), b-comparison between Vehicle control and Sesamol (SES), c-comparison between rotenone (ROT) and rotenone (ROT)+Sesamol (SES)
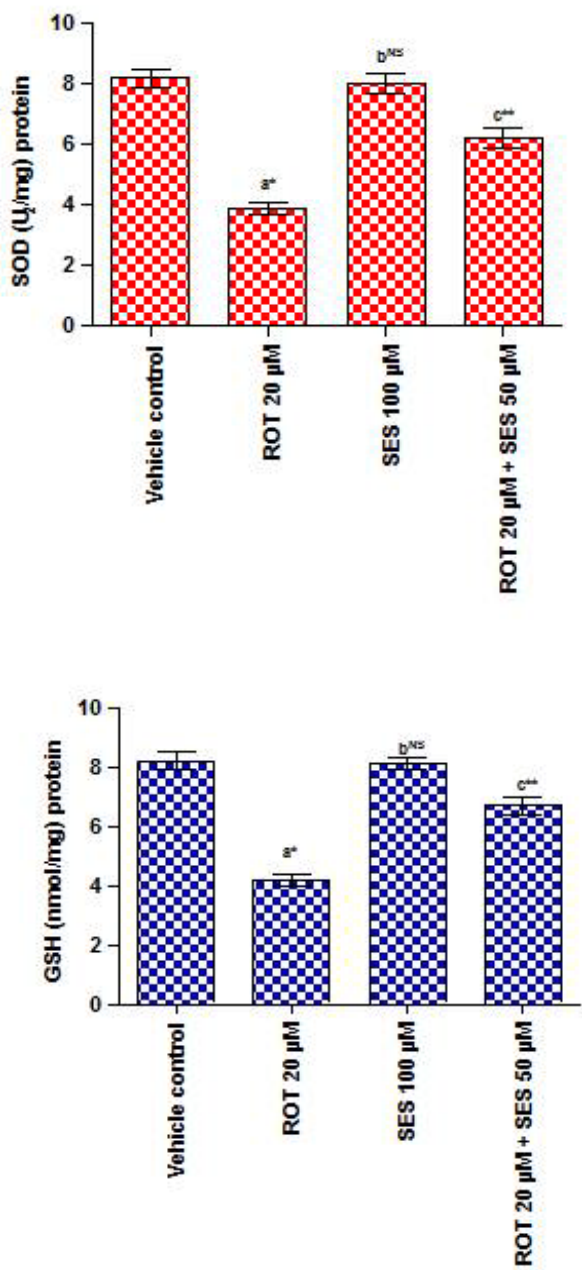

Fig. 8-11: Shows the effect of antioxidative indices (catalase, superoxide dismutase, glutathione peroxidase, glutathione). Statistical significance: ${ }^{*} \mathbf{P}<0.001$ and ${ }^{* *} \mathrm{P}<0.01$; NS-non-significant; $\mathrm{n}=3$, $\mathrm{U1}-\mu$ moles of hydrogen peroxide utilized/minute/mg of protein, $U 2$ Enzyme concentration required for $50 \%$ inhibition of nitroblue tetrazolium reduction in 1 minute, $U 3-\mu$ moles of glutathione utilized/minute/mg of protein, a comparison between Vehicle control and Rotenone (ROT), b-comparison between Vehicle control and Sesamol (SES), c-comparison between Rotenone (ROT) and Rotenone (ROT)+Sesamol (SES) 


\section{CONCLUSION}

In conclusion, our results show that SES $(50 \mu \mathrm{M})$ with ROT $(20 \mu \mathrm{M})$ cotreatment protects SH-SY5Y cells against ROT-induced cell death by ameliorating the ROS production, mitochondrial dysfunction and nuclear damage. SES as an antioxidant has a therapeutic effect to prevent cell death in SH-SY5Y cells. Further studies are being carried out with the animal model to evaluate the neuroprotective effect of SES.

\section{ACKNOWLEDGEMENT}

The authors thank the Department of Science and Technology (DST) for financial support in the form of DST-INSPIRE fellowship.

\section{ABBREVIATION}

PD, Parkinson's disesase; ROT, Rotenone; MPTP, (1-methyl-4phenyl-1,2,3,6-tetrahydropyridine; 6-OHDA, 6-hydroxydopamine; LDOPA, (L-dihydroxy phenylalanine); SES, Sesamol; MTT, 3-(4,5dimethylthiazol-2-yl)-2,5-diphenyl-tetrazolium bromide; DMSO, Dimethyl sulphoxide; DMEM, Dulbecco's modified Eagle's medium; FBS, Fetal bovine serum; NCCS, National Centre for Cell Science; ROS, Reactive oxygen species; DCFH-DA, dichlorofluorescein diacetate; PBS, Phosphate-buffered saline; DAPI, 4',6-diamidino-2-phenylindole; TBARS, Thiobarbituric acid reactive substances, CAT, Catalase; SOD, Superoxide dismutase; NADH, Nicotinamide adenine dinucleotide; PMS, Phenazine methosulphate; NBT, Nitroblue tetrazolium; GPx, Glutathione peroxidase; EDTA, Ethylenediamine-tetraacetic acid; GSH, Glutathione; DTNB, 5, 5'-dithiobis-2-nitro-benzoic acid.

\section{CONFLICTS OF INTERESTS}

\section{Declared none}

\section{REFERENCES}

1. Bobby T, Flint Beal M. Parkinson's disease. Hum Mol Genet 2007;16:183-94.

2. Bove J, Prou D, Perier C, Przedborski S. Toxin-induced models of Parkinson' disease. NeuroRx 2005;2:484-94.

3. Dhillon AS, Tarbutton GL, Levin JL, Plotkin GM, Lowry LK, Nalbone JT, et al. Pesticide/environmental exposures and Parkinson's disease in East texas. J Agromedicine 2008;13:37-48.

4. Brown TP, Rumsby PC, Capleton AC, Rushton L, Levy LS. Pesticides and Parkinson's disease-Is there a link? Environ Health Perspect Rev 2006;114:156-64.

5. Singer TP, Ramsay RR. The reaction sites of rotenone and ubiquinone with mitochondrial NADH dehydrogenase. Biochim Biophys Acta 1994;1187:198-202.

6. Alam M, Schmidt WJ. Rotenone destroys dopaminergic neurons and induces Parkinsonian symptoms in rats. Behav Brain Res 2002;136:317-24.

7. Sherer TB, Kim JH, Betarbet R, Greenamyre JT. Subcutaneous rotenone exposure causes highly selective dopaminergic degeneration and alpha-synuclein aggregation. Exp Neurol 2003;179:9-16.

8. Cannon JR, Tapias VM, Na HM, Honick AS, Drolet RE, Greenamyre TJ. A highly reproducible rotenone model of Parkinson's disease. Neurobiol Dis 2009;34:279-90.

9. Huot P, Johnston TH, Koprich JB, Fox SH, Brotchie JM. The pharmacology of L-DOPA-induced dyskinesia in Parkinson's disease. Pharmacol Rev 2013;65:171-222.

10. Fakhrudin N, Khairunnisa SY, Azzahra A, Ajiningtyas RJ. Study of radical scavenger activity, total phenol and flavonoid contents of Artocarpus altilis leaves extracts. Int J Curr Pharm Res 2016;8 Suppl 5:352-6.

11. Suja KP, Jayalekshmy A, Arumughan C. Free radical scavenging behavior of antioxidant compounds of sesame (Sesamum indicum L.) in DPPH $(*)$ system. J Agric Food Chem 2004;52:912-5.

12. Khadira Sereen A, Vijayalakshmi K. Antioxidant potential and reducing property of sesamol. Int J Pharm Res Bio-Sci 2013;2:465-74.

13. Prasad NR, Mahesh T, Menon VP, Jeevanram RK, Pugalendi KV. Photoprotective effect of sesamol on uvb-radiation-induced oxidative stress in human blood lymphocytes in vitro. Environ Toxicol Pharmacol 2005;20:1-5.
14. Kapadia GJ, Azuine MA, Tokuda H, Takasaki M, Mukainaka T, Konoshima T, et al. Chemopreventive effect of resveratrol, sesamol, sesame oil and sunflower oil in the Epstein Barr virus early antigen activation assay and the mouse skin two-stage carcinogenesis. Pharmacol Res 2002;45:499-505.

15. Hsu DZ, Chen KT, Li YH, Chuang YC, Liu MY. Sesamol delays mortality and attenuates hepatic injury after cecal ligation and puncture in rats: the role of oxidative stress. Shock 2006;25:52832.

16. Jeng KC, Hou RC, Wang JC, Ping LI. Sesamin inhibits lipopolysaccharide-induced cytokine production by suppression of p38 mitogen-activated protein kinase and nuclear factor kappa B. Immunol Lett 2005;97:101-6.

17. Sharma S, Kaur IP. Development and evaluation of sesamol as an antiaging agent. Int J Dermatol 2006;45:200-8.

18. Kumar B, Kuhad A, Chopra K. Neuropharmacological effect of sesamol in unpredictable chronic mild stress model of depression: behavioral and biochemical evidence. Psychopharmacology 2011;214:819-28.

19. Hong Rong XIE, Lin Sen HU, Guo Yi LI. SH-SY5Y human neuroblastoma cell line: in vitro cell model of dopaminergic neurons in Parkinson's disease. Chin Med J 2010;123:1086-92.

20. Biedler JL, Helson L, Spengler BA. Morphology and growth, tumorigenicity and cytogenetics of human neuroblastoma cells in continuous culture. Cancer Res 1973;33:2643-52.

21. Van Meerloo J, Kaspers GJ, Cloos J. Cell sensitivity assays: the MTT assay. Methods Mol Biol 2011;731:237-45.

22. Song JX, Choi MY, Wong KC, Chung WW, Sze SC, Ng TB, et al. Baicalein antagonizes rotenone-induced apoptosis in dopaminergic SH-SY5Y cells related to Parkinsonism. Chin Med 2012;7:1-9.

23. Wang H, Joseph JA. Quantifying cellular oxidative stress by dichlorofluorescein assay using microplate reader. Free Radical Biol Med 1999;27:612-6.

24. Baracca A, Sgarbi G, Solaini G, Lenaz G. Rhodamine 123 as a probe of mitochondrial membrane potential: evaluation of proton flux through F during ATP synthesis. Biochim Biophys Acta 2003;1606:137-46.

25. Morikawa K, Yanagida M. Visualization of individual DNA molecules in solution by light microscopy: DAPI staining method. J Biochem 1981;89:693-6.

26. Ottolenghi A. Interaction of ascorbic acid and mitochondria lipides. Arch Biochem Biophy 1959;79:355-63.

27. Aebi H. Catalase in vitro. Methods Enzymol 1984;105:121-6.

28. Kakkar P, Das B, Viswanathan PN. A modified spectrophotometric assay of superoxide dismutase. Indian J Biochem Biophys 1984;21:130-2.

29. Rotruck JT, Pope AL, Ganther HE, Swanson AB, Hafeman DG, Hoekstra WG. Selenium: biochemical role as a component of glutathione peroxidase. Science 1973;179:588-90.

30. Moron MS, Depierre JW, Mannervik B. Levels of glutathione, glutathione reductase and glutathione-s-transferase in rat lung and liver. Biochim Biophys Acta 1979;582:67-78.

31. Khadira Sereen A, Priya N, Vijayalakshmi K. Effect of sesamol and folic acid on behavioral activity and antioxidant profile of rats induced with 6-hydroxydopamine. Int J Res Pharm Sci 2014-15;6:930-5.

32. Van Gilder RL, Huber JD. Sesamol: a treatment for diabetesassociated blood-brain barrier dysfunction. Post Doc J 2014;2:13-22.

33. Giordano S, Lee J, Darley Usmar VM, Zhang J. Distinct effects of rotenone, 1-methyl-4-phenylpyridinium and 6-hydroxydopamine on cellular bioenergetics and cell death. PLOS One 2012;7:1-11.

34. Anusha C, Sumathi T, Rajkumar M, Kaveri K. Neuroprotective effects of apigenin in human neuroblastoma SH-SY5Y cells against rotenone toxicity: a pilot study. Drug Invent Today 2014;6:6-12.

35. Liu Z, Li T, Yang D, Smith WW. Curcumin protects against rotenone-induced neurotoxicity in cell and Drosophila models of Parkinson's disease. Adv Parkinson's Dis 2013;2:18-27.

36. Lohr JB, Browning JA. Free radical involvement in neuropsychiatric illnesses. Psychopharmacol Bull 1995; 31:159-65. 
37. Liu HQ, Zhu XZ, Weng EQ. Intracellular dopamine oxidation mediates rotenone-induced apoptosis in PC12 cells. Acta Pharmacol Sin 2005;26:17-26.

38. Bender A, Krishnan KJ, Morris CM, Taylor GA, Reeve AK, Perry $\mathrm{RH}$, et al. High levels of mitochondrial DNA deletions in substantia nigra neurons in aging and Parkinson disease. Nat Genet 2006;38:515-7.

39. Chinnaiyan AM, Orth K, O'Rourke K, Duan H, Poirier GG, Dixit VM. Molecular ordering of the cell death pathway. Bcl-2 and Bcl-xL function upstream of the CED-3-like apoptotic proteases. J Biol Chem 1996;271:4573-6.

40. Dhanalakshmi C, Manivasagam T, Nataraj J, Thenmozhi AJ, Musthafa ME. Neuroprotective role of vanillin, a natural phenolic compound, on rotenone-induced neurotoxicity in SH-SY5Y neuroblastoma cells. J Evidence-Based Complementary Altern Med 2015;1-11. Doi:10.1155/2015/626028

41. Kim HJ, Song JY, Park HJ, Park HK, Yun DH, Chung JH. Naringin protects against rotenone-induced apoptosis in human neuroblastoma SH-SY5Y cells. Korean J Physiol Pharmacol 2009;13:281-5.

42. Lin TK, Chen SD, Chuang YC, Lin HY, Huang CR, Chuang JH, et al. Resveratrol partially prevents rotenone-induced neurotoxicity in dopaminergic SH-SY5Y cells through induction of heme oxygenase1 dependent autophagy. Int J Mol Sci 2014;15:1625-46.

43. Joshi R, Kumar MS, Satyamoorthy K, Unnikrisnan MK, Mukherjee T. Free radical reactions and antioxidant activities of sesamol: pulse-radiolytic and biochemical studies. J Agric Food Chem 2005;53:2696-703.

44. Prasad NR, Mahesh T, Menon VP, Jeevanram RK, Pugalendi KV. Photoprotective effect of sesamol on uvb-radiation-induced oxidative stress in human blood lymphocytes in vitro. Environ Toxicol Pharmacol 2005;20:1-5.
45. Chandra JG, Rajanikant GK, Rao SK, Shrinath BM. Alteration in the glutathione, glutathione peroxidase, superoxide dismutase and lipid peroxidation by ascorbic acid in the skin of mice exposed to fractioned gamma radiation. Clin Chim Acta 2003;332:111-21.

46. Eom SA, Kim DW, Shin MJ, Ahn EH, Chung SY, Sohn EJ, et al. Protective effects of PEP-1-catalase on stress-induced cellular toxicity and MPTP-induced Parkinson's disease. BMB Rep 2015;48:395-400.

47. Zhou Q, Liu C, Liu W, Zhang H, Zhang R, Liu J, et al. Rotenone induction of hydrogen peroxide inhibits mTOR-mediated S6K1 and 4E-BP1/eIF4E pathways, leading to neuronal apoptosis. Toxicol Sci 2015;143:81-96.

48. Greenlund LJ, Deckwerth TL, Johnson EM Jr. Superoxide dismutase delays neuronal apoptosis: a role for reactive oxygen species in programmed neuronal death. Neuron 1995;14:303-15.

49. Dewanjee S, Maiti A, Sahu R, Dua TK, Mandal V. Effective control of type 2 diabetes through antioxidant defense by edible fruits of Diospyros peregrine. J Evidence Based Complementary Altern Med 2009;2011:1-7.

50. Kale MA, Bindu SM, Khadkikar P. Role of antioxidants and nutrition in oxidative stress: a review. Int J Appl Pharm Rev $2015 ; 7: 1-4$

51. Isenberg JS, Klaunig JE. The role of mitochondrial membrane permeability transition in rotenone-induced apoptosis in liver cells. Toxicol Sci 2000;53:340-51.

\section{How to cite this article}

- Rohini D, Vijayalakshmi K. Sesamol antagonizes rotenoneinduced cell death in SH-SY5Y neuronal cells. Int J Pharm Pharm Sci 2016;8(12):72-77. 